\title{
Application Research of Engineering Mechanics Mixed Teaching Model Based on Rain Classroom of Intelligent Teaching Tools
}

\author{
Yu Dong \\ School of Management Science and Engineering \\ Shandong Technology and Business University \\ Yantai, Shandong, China
}

\begin{abstract}
With the development of the Internet, current teaching methods of higher education have also undergone significant changes. Based on the common problems in the traditional teaching process of engineering mechanics in colleges and universities, a hybrid teaching mode that combines traditional teaching with networked teaching was explored. The functions and characteristics of the rain classroom intelligent teaching tools were introduced, and teaching activities and evaluation methods of engineering mechanics courses were designed based on the rain classroom, which would provide a reference for the hybrid teaching reform of other courses.
\end{abstract}

Keywords-insert hybrid teaching; engineering mechanics; rain classroom; intelligent teaching tools; teaching activities

\section{INTRODUCTION}

Mechanics is an important foundation for engineering students. Engineering mechanics is a basic course for engineering majors that is closely related to engineering technology. It plays a pivotal role in the professional talent training program such as safety engineering and the curriculum system of science and engineering university education. It is the link between basic courses and professional courses.

\section{TEACHING PROBLEMS OF ENGINEERING MECHANICS COURSE}

The problems in the course of engineering mechanics can be summarized into the following three aspects [1].

\section{A. The Student Side}

The students problem is mainly reflected in the lack of understanding of the importance of engineering mechanics courses. Most of the engineering mechanics courses are offered in the second or third semester of the university. Because students have not fully contacted the professional courses, they do not have a general understanding of the curriculum system of the major. Therefore, the importance of the engineering mechanics curriculum in their mind is insufficient. Some students think that Engineering mechanics is just a basic lesson, and it doesn't help much to the majors they learn.

\section{B. The Teacher Side}

The traditional teaching method has a single form, with teachers as the mainstay, the classroom is boring, the students are tempted to think and passively accept. This kind of teaching method has the drawback of cramming, and the teaching quality is not high. In addition, there is a lack of time for the students to think about reflective problems and the lack of time for practice. The after-school assignments are single and the students deal with few things. Over time, students are tired of learning or even giving up the course of engineering mechanics, so the teaching effect is poor.

\section{The Assessment Side}

The traditional engineering mechanics course adopts the assessment method of "daily grades + test scores". Students do not pay attention to the daily grades, and often take the form of temporary assault review before the exam. Since the test questions are basically a reprint of the example questions, the students use the formulas of the mechanical mechanism, and cannot flexibly combine the knowledge points of the course with the actual engineering practice. This type of assessment deviates from the student's goal of training the application ability.

\section{INTRODUCTION TO THE RAIN CLASSROOM OF INTELLIGENT TEACHING TOOLS}

In view of the problems existing in the current engineering mechanics course teaching, it is of great practical significance to explore a hybrid teaching mode that combines traditional teaching with networked teaching to improve the teaching quality of engineering mechanics [2].

The rain classroom is a intelligent teaching tool jointly developed by Xuetang Online and Tsinghua University Online Education Office. The purpose is to enhance the classroom teaching experience, and to make teachers and students more interactive and more convenient. The rain classroom has the following advantages, and its function is shown in Fig. 1. 
- Flexible pre-course learning. The rich teaching resources are easily inserted into the slides and pushed to the students WeChat anytime, anywhere.

- Quick class test. One-click to send the exercises into the PPT, can be renewed in a limited time, can be taught and tested at any time.

- Innovative teacher-student interaction. bullet screen, submission, classroom red envelopes, random roll call, large class teaching can also make everyone express with bullet screen.
- Perfect job questions. Subjective and objective questions, voting questions, attachment answers, photo uploads, and voice responses to meet different job requirements.

- Panoramic data drive. Provide teachers with full-cycle analysis of teaching data. Everything "before class - in class - after class" can be seen.

- Really understand teaching. The Ministry of Education's Online Education Research Center focuses on research topics, deconstruct and innovate teaching.

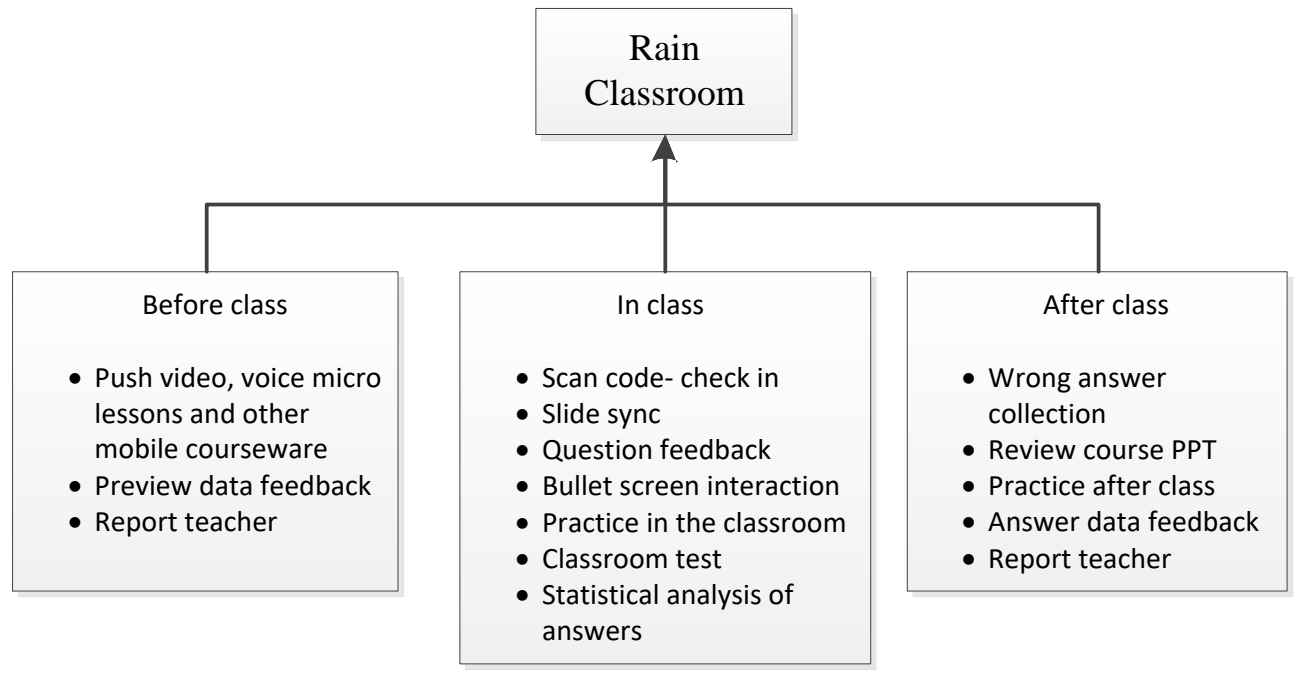

Fig. 1. Schematic diagram of function of the rain classroom

Based on the above advantages, rain classroom integrates complex information technology into PowerPoint and WeChat, and establishes a bridge between extracurricular preparation and classroom teaching, so that classroom interaction never goes offline. Using the rain class, teachers can push the pre-study courseware with MOOC videos, exercises, and voices to the student's mobile phone, and the teachers and students can communicate and feedback in time; the real-time answering and bullet screen interaction in the classroom provides perfect solution for the traditional classroom teaching teacher-student interaction. Rain classroom scientifically covers every teaching session before class -in class - after class, providing complete threedimensional data support for teachers and students, personalized reports, automatic task reminders, to make teaching and learning more clear. Therefore, the teaching quality of engineering mechanics, the students' classroom enthusiasm and learningefficiency can be better improved withthe application of the hybrid teaching mode of engineering mechanics based on the intelligent teaching tool rain classroom[3].

\section{DESIGN AND APPLICATION OF TEACHING ACTIVITY OF ENGINEERING MECHANICS COURSE BASED ON RAIN CLASSROOM}

Through the realization of teachers and students in the teaching activities of engineering mechanics in the past, combined with the problems existing in the traditional teaching of engineering mechanics, the teaching activities of engineering mechanics based on the rain classroom were designed, and the teachers and students were recognized in practice[4]. The design of the teaching activities of the rain classroom is shown in Fig. 2.

In addition, for the course assessment, a formative assessment method is adopted, that is, the total score of the course is formed by the usual assessment $(40 \%)$ and the final exam $(60 \%)$. The usual grade design consists of: self-learning and test scores in the rain classroom before class (30\%), inclass and after-school rain classroom exercises and test scores $(30 \%)$, homework assignments $(20 \%)$, class participation and attendance results $(20 \%)$ are the four major parts. Exploring the adoption of "diversified and integrated" assessment methods, paying attention to the assessment of students' "online mobile app + offline homework + class exercises and tests", and effectively monitoring students" "learning process and improving students' enthusiasm and autonomy in learning[5]. 


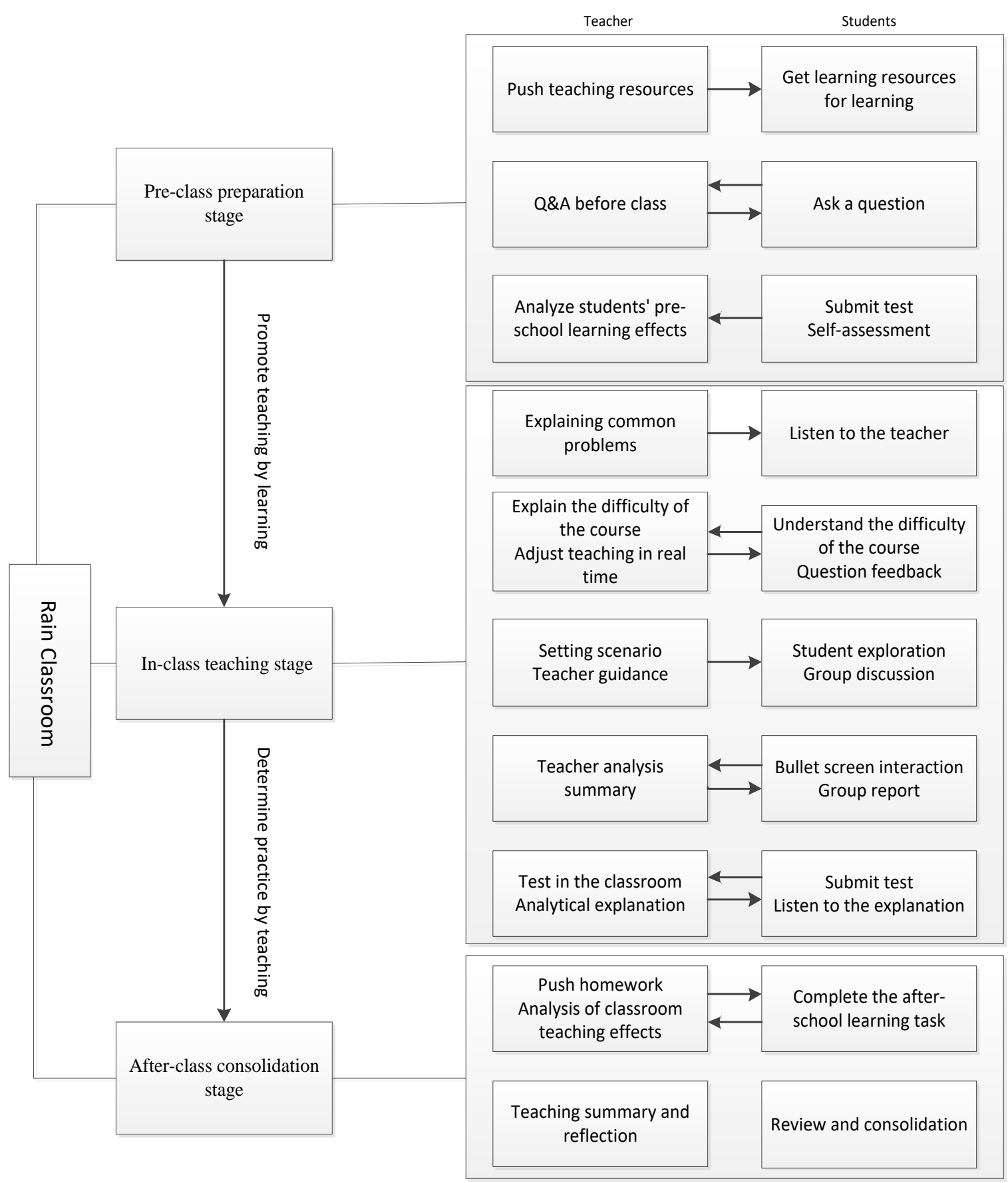

Fig. 2. Design of teaching activity of the rain classroom intelligent tools

\section{CONCLUSION}

In summary, the arrival of the "Internet + " era has provided the education industry with abundant resources. The emergence of the rain classroom represents the new stage of "Internet + Blackboard + Multimedia + Mobile Terminal". Applying the mixed classroom teaching mode of rain classroom to the teaching process of engineering mechanics is of great significance to the cultivation of students' learning ability and the efficiency of teachers' teaching. The reform of engineering mechanics curriculum needs long-term exploration and continuous improvement, in order to play an important role in cultivating the required applied talents.

\section{ACKNOWLEDGMENT}

This work was financially supported by the Youth Foundation of Shandong Technology and BusinessUniversity No.2015QN014, and the PhD Research Startup Foundation of Shandong Technology andBusiness University No. BS201522. 


\section{REFERENCES}

1] C. B.Wei. Reform and practice of engineering mechanics classroom teaching in applied undergraduate colleges, Contemporary Education Research and Teaching Practice, vol. 09 pp:218-220, 2017.

[2] D. Min. Application research of "rain classroom" hybrid teaching mode under the background of "internet +", Journal of Higher Education, vol.09 pp. 100-102, 2019

[3] G. Yong. Engineering Mechanics Teaching Reform Measures under the Background of Informationization, Journal of Higher Education, vol. 14 pp. 124-126, 2019.

[4] Z. F. Xin. Instructional design and practice research based on intelligent teaching tools of rain classroom - taking the course named foundation of television programming as an example, Shenyang Normal University, pp. 20-23, 2018.

[5] Y. Kang. Research on the hybrid teaching mode based on rain class, Think Tank Era, vol. 35 pp. 289-291, 2018. 